\title{
Comprehensive Fuzzy Evaluation of Agricultural Innovation Ability in Science and Technology in Lianyungang, China
}

\author{
Chunjiang Zhu \\ School of Public Administration \\ Lianyungang Technical College \\ Lianyungang, Jiangsu Province, China, 222006 \\ jszcj@126.com
}

\author{
Surendra P. Singh ${ }^{\mathrm{a}}$, Sammy L. Comer ${ }^{\mathrm{b}}$ \\ School of Agriculture Human, and Natural Sciences, \\ Tennessee State University \\ Nashville, TN, USA, 37209 \\ a ssingh@tnstate.edu, bs scomer@ tnstate.edu
}

\begin{abstract}
An evaluation model was developed to evaluate the ability of agricultural innovation in science and technology using fuzzy mathematics method. The core component of the model included a fuzzy relation matrix of the evaluation indexes based on membership function. The model was applied to Lianyungang, China as a case study. The result showed that the comprehensive agricultural innovation ability in science and technology in Lianyunguang, China is in the middle level, which is basically consistent with the fact. This study demonstrated that the comprehensive fuzzy evaluation model is highly operable and feasible.
\end{abstract}

Keywords- fuzzy evaluation, agricultural innovation ability, empirical case study

\section{INTRODUCTION}

Agriculture is the foundation of the national economy in China, and agricultural innovation in science and technology is the power source for promoting the development of the national economy. Agricultural technological innovation ability is the core factor of promoting agricultural modernization [1].

The concept of "technological innovation" was proposed by Austrian-American economist A.J. Schumpeter in 1912 [2]. Research on technology innovation in China began in the eighties of the 20th century. Few studies have attempted to evaluate the agricultural innovation in science and technology, especially in a quantitative way, mainly using cluster analysis [3], weighted linear regression analysis [4], and so on. These studies have improved out understanding; however, agricultural innovation ability in science and technology involves many different components such as agricultural innovation policy, agricultural innovation resources and allocation, and the outputs of agricultural innovation. Many evaluation systems have certain fuzziness, and agricultural innovation ability in science and technology itself is actually a fuzzy value. Therefore the utilization of fuzzy mathematics method to assess agricultural innovation ability in science and technology has both scientific value and practical applications.

\section{ESTABLISHMENT OF EVALUATION INDEX SYSYTEM}

Establishment of evaluation index system for agricultural innovation ability in science and technology should follow some basic principles, including scientific principle, simple intelligible principle, accurate and uniform calculation method, and operability. The opinions from experts can also be used. In this study, there were 86 experts and scholars in 16 investigative units involved during the project research team survey period from August to November in 2012.

The 16 investigation units included both local, national and international units. Such as Lianyungang Municipal Agricultural Office; Lianyungang Agricultural Committee; Lianyungang Science and Technology Bureau; Chongqing Normal University; Northeast Agricultural University; Tennessee State University (in the United States), and so on.

The 16 second-level indexes of agricultural innovation ability in science and technology were defined within three subsystems: policy subsystem, resources and allocation subsystem, and output subsystem. The policy subsystem consists of two second-level indexes: funds from government departments, research and development expense deduction tax relief. The resources and allocation subsystem consists of eight second-level indexes: number of R\&D persons, number of scientific and technical institutions, research funding, rural labor skills training, technology acquisition and improvement, agricultural information service coverage, patent ownership transfer and licensing, scientific and technological cooperation projects accounting for the ratio of science and technology projects. The output subsystem consists of the six second-level indexes: agricultural science and technology progress contribution rate, number of published scientific papers, R\&D projects, number of invention patents, forming state or industry standards, agricultural exports amount growth rate.

\section{FUZZY MATHEMATICAL MODEL AND DATA PROCESSING}

\section{A. Fuzzy mathematical model}

The following is a detailed description of the mathematical model of fuzzy comprehensive evaluation[5]. Mathematical model uses a function $V=\left\{v_{1}, v_{2}, \cdots v_{m}\right\}$ to represent the evaluation set consisting of the evaluation results by the evaluation object.

The evaluational set (depicting strong or weak) to the agricultural innovation ability in science and technology is: $V=\{$ strongest ability, stronger ability, general ability, worse ability, worst ability $\}$, recorded as $V=\left\{v_{1}, v_{2}, v_{3}, v_{4}, v_{5}\right\}$ 
$=\{1,2,3,4,5\}$, in which $1,2,3,4$, or 5 is expressed as "the fuzzy number" of the agricultural innovation ability in science and technology.

Each subsystem index evaluation element set is set as $V_{j}=\{1,2, \cdots m\}$, and $m$ is the number of levels or review grades. If the value $m$ is 5 , then five levels of evaluation can be divided into strongest ability, stronger ability, general ability, worse ability, worst ability.

The evaluation level vector $C$ and the comprehensive evaluation value of the comprehensive ability of agricultural innovation in science and technology $F$ are:

$$
C=A^{*} R
$$

$F=V^{*} C^{\prime}$

Where $A$ is weight vector of the first-level index evaluation factors $v_{1}, v_{2}, \cdots v_{m}$ for the comprehensive innovation ability of agricultural innovation in science and technology. $R$ is a matrix from the second-level index factors evaluation result.

$R=\left[\begin{array}{c}B_{1} \\ B_{2} \\ \cdot \\ \cdot \\ \cdot \\ B_{\mathrm{n}}\end{array}\right]=\left[\begin{array}{cccc}b_{11} & b_{12} & \ldots & b_{1 \mathrm{~m}} \\ b_{21} & b_{22} & \ldots & b_{2 \mathrm{~m}} \\ \cdot & \cdot & \ldots & \cdot \\ \cdot & \cdot & \ldots & \cdot \\ \cdot & \cdot & \ldots & \cdot \\ b_{\mathrm{n} 1} & b_{\mathrm{n} 2} & \ldots & b_{\mathrm{nm}}\end{array}\right]=\left(b_{i j}\right)_{n \times m}$

Where $b_{i j}$ is the sum of product of the weighted

$i^{\text {th }}$ second-level index times the $j^{\text {th }}$ membership value of this second-level index.

$b_{i j}=\coprod_{k=1}^{m}\left(x_{i k} \prod \mu_{k j}\right)$

Namely $b_{i j}$ is evaluation value for the $i^{\text {th }}$ factor and the $j$-level. Where $i=1,2, \cdots, n, \quad j=1,2, \cdots, m, \quad x_{i k}$ is the weight of the second-level indexes of evaluation of agricultural experts, and $\mu_{k j}$ is the membership function value of the second-level evaluational set.

\section{B. Determination of membership function}

The index evaluation criteria and determination of membership function for "agricultural information service coverage" in "the innovation of agricultural in science and technology resources and configuration subsystem” is listed in Table 1.Similarly, the other index evaluation criteria and determination of membership function in the agricultural innovation system in science and technology can be determined.
TABLE 1 THE INDEX EVALUATION CRITERIA OF AGRICULTURAL INFORMATION SERVICE COVERAGE UNIT:\%

\begin{tabular}{c|c|c|c|c}
\hline $\begin{array}{c}\text { worst } \\
\text { ability }\end{array}$ & $\begin{array}{c}\text { worse } \\
\text { ability }\end{array}$ & $\begin{array}{c}\text { general } \\
\text { ability }\end{array}$ & $\begin{array}{c}\text { stronger } \\
\text { ability }\end{array}$ & $\begin{array}{c}\text { strongest } \\
\text { ability }\end{array}$ \\
\hline$\leqslant 40$ & $40 \sim 100$ & $100 \sim$ & $200 \sim$ & $\geqslant 300$ \\
& & 200 & 300 & \\
\hline
\end{tabular}

On the basis of ability distribution presented in Table 1, agricultural information service coverage membership functions of "agricultural information service coverage" index in "the innovation of agricultural in science and technology resources and configuration subsystem" are defined as follows:

The weakest membership function $\mu_{26}^{(1)}(x)$ of the innovation of agricultural in science and technology resources and allocation is calculated using

$\mu_{26}^{(1)}(x)=\left\{\begin{array}{lc}1 & x \leq 20 \\ \frac{60-x}{40} & 20<x \leq 60 \\ 0 & x>60\end{array}\right.$

Weaker membership function $\mu_{26}^{(2)}(x)$ of the innovation of agricultural in science and technology resources and configuration is calculated using $\mu_{26}^{(2)}(x)=\left\{\begin{array}{lc}0 & x \leq 20 \\ \frac{x-20}{40} & 20<x \leq 60 \\ 1 & 60<x \leq 80 \\ \frac{140-x}{60} & 80<x \leq 140 \\ 0 & x>140\end{array}\right.$

General membership function $\mu_{26}^{(3)}(x)$ of the innovation of agricultural in science and technology resources and configuration is calculated using

$$
\mu_{26}^{(3)}(x)=\left\{\begin{array}{lc}
0 & x \leq 80 \\
\frac{x-80}{60} & 80<x \leq 140 \\
1 & 140<x \leq 160 \\
\frac{240-x}{80} & 160<x \leq 240 \\
0 & x>240
\end{array}\right.
$$

Stronger membership function $\mu_{26}^{(4)}(x)$ of the innovation of agricultural in science and technology resources and configuration is calculated using

$\mu_{26}^{(4)}(x)=\left\{\begin{array}{lc}0 & x \leq 160 \\ \frac{x-160}{80} & 160<x \leq 240 \\ 1 & 240<x \leq 260 \\ \frac{340-x}{80} & 260<x \leq 340 \\ 0 & x>340\end{array}\right.$ 
The strongest membership function $\mu_{26}^{(5)}(x)$ of the innovation of agricultural in science and technology resources and configuration is calculated using

$\mu_{26}^{(5)}(x)= \begin{cases}0 & x \leq 260 \\ \frac{x-260}{80} & 260<x \leq 340 \\ 1 & x>340\end{cases}$

\section{Calculation of fuzzy evaluation vector and} comprehensive evaluation value

The index values of Lianyungang agriculture innovation system in science and technology can be found in Lianyungang Statistical Yearbook 2010, 2010 Government Annual report, and the data from the Agriculture Committee and Agriculture Office of Lianyungang City in China.

Calculation of "agricultural information service coverage" membership in "the innovation of agricultural in science and technology resources and configuration subsystem" is shown below as an example, by using an index value of 61.48, and using the formula (5), formula (6), formula (7), formula (8) and formula (9), the membership values can be calculated as follows:

$$
\begin{aligned}
& \mu_{11}^{(1)}(x)=0, \quad \mu_{11}^{(2)}(x)=1 \quad, \quad \mu_{11}^{(3)}(x)=0, \\
& \mu_{11}^{(4)}(x)=0, \quad \mu_{11}^{(5)}(x)=0
\end{aligned}
$$

Thus, the membership of "agricultural information service coverage" is $(0,1,0,0,0)$.

Similarly, the memberships of other indexes can be calculated (Attached Table 2).

The memberships belonging to second-level indexes set are:

$$
\begin{aligned}
& R_{1}=\left[\begin{array}{ccccc}
0 & 0 & 0.694 & 0.306 & 0 \\
0.8605 & 0.1395 & 0 & 0 & 0
\end{array}\right] \\
& R_{2}=\left[\begin{array}{llllll}
0 & 0 & 0 & 0.5625 & 0.4375 \\
0 & 1 & 0 & 0 & 0 \\
0 & 0 & 0.8413 & 0.1587 & 0 \\
0 & 0.265 & 0.735 & 0 & 0 \\
0 & 0 & 0.4302 & 0.5698 & 0 \\
0 & 1 & 0 & 0 & 0 \\
0.15 & 0.85 & 0 & 0 & 0 \\
0 & 0 & 0 & 0.925 & 0.075
\end{array}\right] \\
& R_{3}=\left[\begin{array}{ccccc}
0 & 0.498 & 0.502 & 0 & 0 \\
0 & 0.2 & 0.8 & 0 & 0 \\
0 & 0.7 & 0.3 & 0 & 0 \\
0 & 0 & 0.9 & 0.1 & 0 \\
0 & 0 & 1 & 0 & 0 \\
0 & 0 & 0.5833 & 0.4167 & 0
\end{array}\right]
\end{aligned}
$$

The second-level and the first-level weight vectors by 86 experts are:

$A_{1}=\left(x_{11}^{\prime}, x_{12}^{\prime}\right)=(0.632253012,0.367746988)$

$A_{2}=\left(x_{21}^{\prime}, x_{22}^{\prime}, x_{23}^{\prime}, x_{24}^{\prime}, x_{25}^{\prime}, x_{26}^{\prime}, x_{27}^{\prime}, x_{28}^{\prime}\right)$

$=(0.125903614,0.108795181,0.209879518,0.130120482$,

$0.12373494,0.110481928,0.09246988,0.098614458)$

$A_{3}=\left(x_{31}^{\prime}, x_{32}^{\prime}, x_{33}^{\prime}, x_{34}^{\prime}, x_{35}^{\prime}, x_{36}^{\prime}\right)=(0.228072289,0.141807229$, 0.177349398, 0.127951807, 0.157108434, 0.167710843)

$A=\left(x_{1}^{\prime}, x_{2}^{\prime}, x_{3}^{\prime}\right)=(0.281214848,0.337457818,0.381327334)$

Then $A_{1}, A_{2}, A_{3}, R_{1}, R_{2}, R_{3}$ are substituted in formula (4), and the second-level fuzzy evaluation vector $R$ can be determined.

$B_{1}=A_{1} * R_{1}=(0.316446283$, 0.051300705, 0.43878359,0.193469422,0)

$B_{2}=A_{2} * R_{2}=(0.024918675,0.223563253$,

$0.512835542,0.265851205,0.062478916)$

$B_{3}=A_{3} * R_{3}=(0,0.266086024,0.651233687,0.197836916,0)$

$R=\left[\begin{array}{l}B_{1} \\ B_{2} \\ B_{3}\end{array}\right]=$

$\left[\begin{array}{ccccc}0.316446283 & 0.051300705 & 0.43878359 & 0.193469422 & 0 \\ 0.024918675 & 0.223563253 & 0.512835542 & 0.265851205 & 0.062478916 \\ 0 & 0.266086024 & 0.651233687 & 0.197836916 & 0\end{array}\right]$

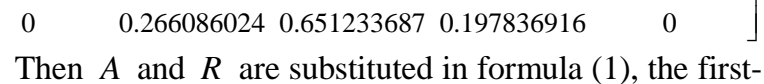
level fuzzy evaluation vector $C$ can be determined.

$C=A^{*} R=(0.129078619,0.169832869$,

$0.523517122,0.219123424,0.021083999)$

Then $V=\{1,2,3,4,5\}$ and $C^{\prime}$ are substituted in formula (2).

$$
F=V * C^{\prime}=3.02
$$

Because the evaluational set is $V=\{1,2,3,4,5\}$, in which $1,2,3,4$, or 5 is expressed "worst ability, worse ability, general ability, stronger ability, strongest ability", and $F$ is 3.02, in accordance with the proximity principle of fuzzy pattern recognition, the comprehensive ability of agricultural innovation in science and technology in Lianyungang City, China is basically at the middle level.

\section{CONCLUSIONS}

(1)The comprehensive evaluation value of agricultural innovation ability in science and technology is 3.02. The proximity principle of fuzzy pattern recognition shows that Lianyunguang, China has general agricultural innovation ability in science and technology, which is basically consistent with the fact. 
(2) The evaluation results demonstrate the operability and feasibility of this comprehensive fuzzy evaluation model for evaluating agricultural innovation ability in science and technology. This model can also be used in other similar cities and under similar conditions.

\section{ACKNOWLEDGEMENTS}

This study was sponsored by Jiangsu Overseas Research \& Training Program for University Prominent Young \& Middle-aged Teachers and Presidents (2011), Jiangsu Province “333” High-level Talents Program(2011), and University Philosophical and Social Science Research Program of the Education Department of Jiangsu province, China, in 2010 (No. 2010SJD630050). Major parts of this study were completed when Dr. Zhu is served as a visiting scholar at the College of Agriculture, Human and Natural Sciences, Tennessee State University, USA.

\section{REFERENCES}

[1] Lihua Ma, Huizhe Yan, and Pingjian Yan. Measuring Research on County Agricultural Technological Innovation Ability Index[J]. Asian Agricultural Research,2011,3(6):16-20

[2] Hongwen Hu. A Theoretic Research and Empiric Analysis on Agricultural Technological Innovation [D]. Wuhan University of Technology, 2003 (in Chinese)

[3] Yuchun Zhu, and Zengji Huang. The Regional Comparison and Analysis on the Innovation Capability of Agricultural Science and Technology in China [J]. Commercial Research, 2008(9):133-136 (in Chinese)

[4] Zhijun Zhao, Xiaoming Sun, Shemei Zhang, and Xueguo Yuan. On evaluation method of Agricultural industrialization promoting regional innovation ability on science and technology construction[J]. Journal of Agrotechnical Economics, 2005(3) : 31-34 (in Chinese)

[5] Hao Fan, Hui Ge, Shaoping Lei, Fengling Yan, and Zhenping Huang. Estimation of ecosystem services value based on fuzzy mathematic method [J]. Water Resources Protection, 2011(2):35 (in Chinese)

TABLE 2 THE INDEX VALUE AND MEMBERSHIP AGRICULTURAL INNOVATION SYSTEM IN SCIENCE AND TECHNOLOGY OF LIANYUNGANG CITY IN CHINA

\begin{tabular}{|c|c|c|c|}
\hline & Name of index & Index value & Degree of membership \\
\hline \multirow{2}{*}{$\begin{array}{l}\text { Agricultural } \\
\text { innovation in science } \\
\text { and technology policy } \\
\text { subsystem }\end{array}$} & $\begin{array}{l}\text { using science and technology funds from } \\
\text { government departments / (Ten thousand Yuan) }\end{array}$ & 240.3 & $(0,0,0.694,0.306,0)$ \\
\hline & $\begin{array}{l}\text { research and development expense deduction tax } \\
\text { relief / (Ten thousand Yuan) }\end{array}$ & 127.9 & $(0.8605,0.1395,0,0,0)$ \\
\hline \multirow{8}{*}{$\begin{array}{l}\text { The innovation of } \\
\text { agricultural in science } \\
\text { and technology } \\
\text { resources and } \\
\text { configuration } \\
\text { subsystem }\end{array}$} & number of R\&D persons / (person) & 295 & $(0,0,0,0.5625,0.4375)$ \\
\hline & number of scientific and technical institutions & 20 & $(0,0,1,0,0)$ \\
\hline & research funding / ( Ten thousand Yuan ) & 5476 & $(0,0,0.8413,0.1587,0)$ \\
\hline & $\begin{array}{l}\text { rural labor skills training } / \text { ( Ten thousand } \\
\text { persons) }\end{array}$ & 4.47 & $(0,0.265,0.735,0,0)$ \\
\hline & $\begin{array}{l}\text { technology acquisition and improvement / ( Ten } \\
\text { thousand Yuan) }\end{array}$ & 8279.3 & $(0,0,0.4302,0.5698,0)$ \\
\hline & agricultural information service coverage/ (\%) & 61.48 & $(0,1,0,0,0)$ \\
\hline & patent ownership transfer and licensing / (item ) & 37 & $(0.15,0.85,0,0,0)$ \\
\hline & $\begin{array}{l}\text { Scientific and technological cooperation projects } \\
\text { accounting for the ratio of science and technology } \\
\text { projects / }(\%)\end{array}$ & 83 & $(0,0,0,0.925,0.075)$ \\
\hline \multirow{6}{*}{$\begin{array}{l}\text { Agricultural } \\
\text { innovation science } \\
\text { and technology output } \\
\text { subsystem }\end{array}$} & $\begin{array}{l}\text { agricultural science and technology progress } \\
\text { contribution rate } /(\%)\end{array}$ & 50.04 & $(0,0.498,0.502,0,0)$ \\
\hline & number of published scientific papers & 33 & $(0,0.2,0.8,0,0)$ \\
\hline & $\mathrm{R} \& \mathrm{D}$ projects & 54 & $(0,0.7,0.3,0,0)$ \\
\hline & number of invention patents / (item) & 41 & $(0,0,0.9,0.1,0)$ \\
\hline & forming state or industry standards / (item ) & 12 & $(0,0,1,0,0)$ \\
\hline & agricultural exports amount growth rate / (\%) & 17.5 & $(0,0,0.5833,0.4167,0)$ \\
\hline
\end{tabular}

